\title{
Citizen Media Literacy Education Comparison and Analysis in China and the United States
}

\author{
Wu Hongying \\ (Shunde Polytechnic, Guangdong, Shunde,528300, China)
}

\begin{abstract}
Keywords: Citizens in China and the United States; Media literacy education; Comparison and analysis
\end{abstract}

\begin{abstract}
In the 21st century, with the development of information technology, Internet quietly enters People's Daily life; media tools such as new media become indispensable partners in people's life and learning, which greatly changes people's life style, communicative manners and ways of thinking. The emergence of new media provides people with huge network resources, offers a convenient way of obtaining information, and at the same time provides a platform for people to show themselves. People's personality is made public and developed. In an era of new media and network coverage, people are inseparable from the new media and rely on it, but in the use of its advantages, the new media brings crisis and problems to the human society at the same time. It brings adverse effect to people's life, and the adverse effect has a lot to do with social citizen's media literacy education.
\end{abstract}

\section{INTRODUCTION}

The development of information technology makes people enter an era of information explosion. With the help of the new media, the access to information has become more convenient and fast. Large amount of information is filled in People's Daily life. Some are right information, and some are dregs. Good information can be a positive effect to people's life, while the spread of bad information can bring bad effect to the whole society and people and impose bad impact on people's life and thought, so in the Internet age, citizen's media literacy education is very important. With the popularization of information technology, the Internet and new media in our country, in constant, citizen's media literacy education in the whole did not make the development and progress along with it. In the United States and other western countries, citizens' media literacy education is given enough attention. It often begins from primary school in student education, and China should learn from it.

\section{MEDIA LITERACY EDUCATION STATUS IN CHINA AND THE UNITED STATES}

\section{China}

China's media development is not accordance with the development of media literacy education. Media literacy education in China did not get attention in the 1990s. For China, media literacy education is a borrowed word, which does not exist in China. There is a reason for the word being valued in China. In the 1990s, the Internet did not rise. Active media in people's lives are mainly newspapers, radio, television, etc. They were of strong development trend and occupied the fringes of people's life, and were the important way to access to information. A lot of information made a lot of people caught off guard. Lack of the ability of identifying information, people's values and outlook on life had been under great impact and challenges. In addition, with the development of market economy, medium market competition was increasingly fierce. In order to defeat competitors and fight for a seat in the media market, many enterprises, regardless of good or bad news authenticity, provided society with a lot of false and bad information, which fouled the general mood of society and had brought very bad influence on the development of medium and life. In the face of this, due to the poor citizen medium quality, they were successful information receivers but not qualified analyzers and judges for all kinds of information. Based on this situation, Chinese citizen's media literacy education was valued. 
Since the 21 st century, China's media literacy education is still in the initiation stage without a suitable education means and system. Chinese citizens' media literacy education's present situation is not optimistic, and still needs a long way to go in the face of the future.

\section{The U.S.}

Media literacy education in the United States was 30 years earlier than in China. In the early 1960s, the United States began to attach importance to the matter of media quality education. At that time, American TV and movies as well as the spread of network violence, pornographic contents such as teenagers and society brought bad influence to the United States. People's living environment and the growth of the teenagers were worrying. Experts in the United States and school teachers tried every means to reduce the influence of bad information to the students, and strove to create a good social environment. It was this kind of situation which had given rise to the media literacy education in the United States. Media quality education in the United States started not long, but the effect was larger. The media system and media environmental protection and application model in the ' $60 \mathrm{~s}$ was turned to the empowerment mode in the ' $80 \mathrm{~s}$, and at the same time, the schools also carried out corresponding media literacy education to improve the discrimination ability of the students.

\section{CHINA'S MEDIA LITERACY EDUCATION MODES AND MEANS}

\section{The combination of defense and constructive modes}

China's media literacy education, to a great extent, uses the reference of foreign experience. On the basis of absorbing foreign experiences, in combination with the actual conditions of China, China is setting up a defense mode as well as the constructive mode; therefore China's media literacy education is in its infancy. The purpose of China's media literacy education is to raise the public's ability to consciously resist bad information and maximally reduce bad information effect. In addition, promote the citizens to use media, make them have the right and ways to access and use resources. Defense and constructive mode combined with China's media literacy education, media literacy education can be effectively carried out.

Defense mode is the primary mode of media literacy education in many developed countries, and the early guidance idea. For China, media literacy education defense is the necessary stage. Different areas' media literacy is different. The degree of media literacy education between countries is different. In the face of such situation, China must take defense mode as the basis of their media literacy education. With the improvement of the economic development and international status of China, we should achieve flexible model of media literacy education on the basis of defensive protection.

China is in the early stages of education, so actively learn the good experience of abroad and combine with our country actual situation closely to make our country's media literacy education go little detours.

\section{School education}

Media literacy education in China is relatively backward. Although the related school education has been put forward, for now, there is not perfect media literacy education system from our country's elementary school to university. There is no specialized course content for teachers teaching and students learning. Media literacy education system in China doesn't exist at all, and the teacher will happen to educate students. Media literacy education in China has yet to be further developed, and there is also a very big development space and needs.

\section{UNITED STATES' MEDIA EDUCATION IDEAS AND WAYS}

\section{Concept}

(1) Interventionist ideas

Interference is primarily a proactive reasonable guide even intervention for the citizens, especially teenagers contact medium behavior. In a sense, it has similarities with protection defense. With the rapid development of a variety of media, media influence on society and people are 
everywhere. Previous experience in media literacy education facing the new situation completely doesn't work. In the face of this situation and on the basis of using the experience in the United States, the concept of media literacy education with Chinese national characteristics, namely the interventionist idea, is formed.

Interventionist concept mainly aims at the adverse impact of bad information and phenomenon. The concept of intervention practice has brought important influence and impact on America media literacy education. It has profound impact on the United States. The concept of media literacy education is not only supported by American scholars, but also gets the support of a wide range of social organization. Moreover, it also is funded by the U.S. Government and wins widespread mass base. The concept of media literacy education still has important influence and has important implications for the United States.

(2) Culture studies concept

In addition to the concept of interference, there is culture research ideas philosophy. Interference concept is mainly aimed at adverse effects and culture research idea is to guide the public feelings and experience using media. This concept emphasizes civilians' main body status, attaches great importance to the understanding of citizens, and its purpose is to bring convenience and enjoy to citizens of the United States with the media experience. The occurrence of cultural studies concept makes the U.S. shift from interference, protection and defense phase to the direction of protection, preparation and fun. Protection is to exclude bad effects information through media literacy education; Preparation is to improve the ability of people to make better communicate and learning with the use of the media and make media better serve themselves; Pleasure is to make people master the ability to identify information through media literacy education, which makes people access to information and knowledge in happiness.

Concept of media literacy education is constantly changing. This kind of change is inseparable from the media's development, but these ideas can to a great extent, adapt to the rapid updating of media. Media literacy education provides citizens of the United States a good media environment, promotes the healthy development of the media, also has brought convenience to people's life, and provides people with convenient access to information.

Ways

Development of media literacy education in the United States has been very complete, and its media literacy education's main implement site is the schools from elementary school to junior high school, from junior high school to university. It has formed a complete set of media literacy education system, and has special courses and content; In addition to the schools, the main venues, media literacy education not only causes the attention of the school, also causes the attention of the American society, social organization and the United States government, which also have important roles in media literacy education and play important roles.

(1) Schools

1. Teachers' media literacy education. Media literacy education has received the attention in the United States schools. To carry out on media literacy education, first of all, the teachers must first accept media literacy education. As a culture and knowledge spreader, the teacher plays an important role in media literacy education. In the United States, the school teachers never relax media literacy education. At the beginning of media literacy education implementation, they tend to learn by self-study to get to know the content, but self-study is often limited, so the teacher can't deeply understand its importance, and there is no guidance from professional persons, and they have not received related training. They can only rely on their own experience and previous knowledge. The variety of factors led to poor teacher's self-taught effect. Later, with the deepening study of media literacy education, the school provides some education training opportunities to the teachers slowly, and provides some related courses such as TV literacy and information literacy to let the teachers gradually understand the connotation of media literacy education as well as its importance. Let the teachers master how to image analysis and judge the value of information, and constantly improve the level of teacher's media literacy. In the development of the Era and media in the update, media literacy education is a long-term education and is a lifelong learning knowledge. Education 
training is an important way for teachers to study media literacy knowledge. Through training, teachers can realize clearly the important relationship between mass media and media literacy education. In order to improve media literacy of the teachers, the teachers also create a variety of learning styles, such as group cooperation study. Mutual exchanges and mutual discussions between groups give teachers learning motivation. Besides, teachers set up network resource sharing platform, promote exchanges and cooperation between teachers and share resources of media literacy education. So teachers can master more media literacy education resources and lay a solid foundation for the teaching.

2. Students' media literacy education. Teacher is the leader of media literacy education, and students are the subject of media literacy education. Students in media literacy education must actively cooperate; know the importance of media literacy education. Stimulate students' learning motivation, make the students learn to discern between the ability of information, and make them better enjoy the convenience of medium.

(2) Social organizations and the government

School is the base of the United States media literacy education, but the outcomes of media literacy education is inseparable from social organization's effort. This is also the advantage of the United States. In the United States, there are a lot of good media literacy organizations and institutions. Through their own efforts, media literacy education in the United States has created a variety of development ways, which greatly promotes the development of media literacy education in the United States and makes a great contribution to it. Not only that, the U.S. government has given enough attention, funds and policy support, which provide the development advantage of media literacy education in the United States.

\section{CONCLUSION}

With the development of information technology and Internet, media forms are more and more, which impacts all aspects of people's life and learning. The role of media literacy education is more and more important. Media literacy education in China is in the early stages and there is still a long way to go. The development of media literacy education in the United States is very perfect, so our country should learn from the excellent experience modestly to make our country's media literacy education go smoother with little detours.

\section{ACKNOWLEDGMENTS}

2015 annual Foshan Social Science Planning Project: Research on the quality and network literacy of Foshan citizens under the background of "Internet +" , 2015-BZ49;

Shunde Polytechnic "innovation and strong school project" independent innovation ability to improve the type of project: the beauty of the city - citizens quality cooperative cultivation center stage results, 2015-KJZX048

\section{REFERENCES}

[1] Wu Pengze. Contrast research of college students' media literacy education in China and the United States [J]. Journal of Heilongjiang Province Higher Education Research, 2011 practices: 9-12.

[2] Yuan Jun. Media literacy education world view and Chinese model [J]. Journal of the International Press, 2010, 05:23-29.

[3] Chen Xiaohui, Yuan Lei. The status quo and enlightenment of media literacy education in elementary and secondary schools [J]. China Audio-visual Education, 2010,09:26-29.

[4] Wang Wenke, Zhao Li. The development and enlightenment of American media literacy movement [J]. Chinese Journal of Broadcasting and Television, 2007, 05:42-44.

[5] Li Xiaopei. American teens media literacy education experience and revelation [D]. Zhengzhou University, 2014. 